\title{
Research on the Public English Teaching Mode Reform under the Environment of Information Technology
}

\author{
Haipeng Luo \\ Nantong Health College of Jiangsu Provinve,226000 China
}

\begin{abstract}
In this paper, we conduct research on the public English teaching mode reform under the environment of information technology. This article fully draw lessons from successful experience of others, combined with years of practice of the reform of public English, the author expounds the necessity and characteristics of the diversity of public English teaching in high vocational colleges are diversity teaching results, and points out the existing problems and aims to improve students' interest in the learning English to ensure the quality of public English teaching make better service for higher vocational education in teaching English. Our research combines the information technology that is innovative and efficient. The future research orientation is determined in the final conclusion.
\end{abstract}

Keywords- Public English, Mode Reform, Information Technology, General Environment.

\section{Introduction}

Several years of the enrollment expansion in colleges and universities in the recent years, makes the development of higher education in the direction of the "popularization" gradually, this can let more students have the opportunity to receive the higher education. But due to the level of regional basic education is put in very big difference that lead to students knowledge level is uneven, which for some national teaching of recruit students of institutions of higher learning difficulty.

According to the literature review, the influences caused by the enrollment expansion could be summarized as follows. (1) The role and the status of the public English teaching in higher vocational colleges there exists deviations in understanding and evaluation. Because of the public English class teaching hours are determined by the professional teaching and research section, therefore, different professional teaching system and the public English teaching hours are different. (2) The traditional classroom teaching efficiency is low and multimedia classroom teaching effect is poor. Good school teaching hardware, basically use the multimedia in language teaching. Modern teaching equipment does not mean that the teaching effect is definitely improved. (3) Students come from complex, the English level difference and the traditional classroom teaching is difficult to meet the learning need of students. High English level of students find the classroom teaching is very boring, as a waste of time and the teacher wants to find a balance, satisfied the parties that is not an easy thing [1-3].

Vocational English teaching is different from the basic English teaching, and also on the teaching target, teaching content and teaching method is different from the traditional English teaching. It is of higher vocational public English teacher's role and teaching ability put forward higher requirements. Teachers must actively face the challenge, and strive to raise their professional quality and teaching ability. Higher vocational public English teachers in improving English comprehensive application ability and professional level at the same time also need to actively study and understand the basic professional knowledge of related industries to accumulate relevant practical experience.

In order to realize the basic improvement of teaching, improving teaching quality, cannot leave the reform of teaching methods, teaching means. But no advanced ideas, then there can be 
no advanced teaching practice, it is impossible to have good teaching methods or means. Teaching, therefore, first is the change of the concept of the English teaching, the reform of higher vocational teachers should realize the aim of higher vocational college English teaching is to cultivate the students to master the necessary English language knowledge and language skills, have professional information on English reading and translation and the preliminary ability, and to further improve the English application ability to lay a certain foundation. In English teaching, besides should actively play a leading role of the teacher, use of modern teaching means is also inevitable trend. Higher vocational teachers should focus on the student's individual differences, to do according to their aptitude. Ensure that students learn something also asked us to pay attention to every student in the teaching, and care about their individual differences and general development of body and mind, for some shy introverted, poor oral English, students as much as possible to create opportunities for the language practice, the progress of their timely affirmation and encouragement [4].

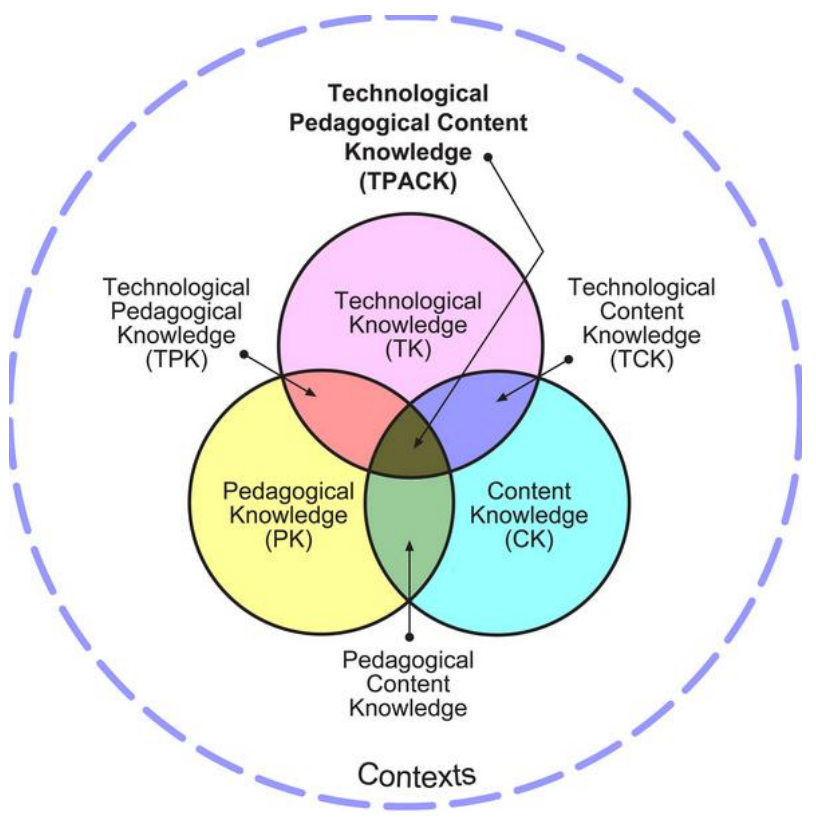

Figure 1. The State-of-the-art Teaching Methodologies
In this paper, we conduct research on the public English teaching mode reform under environment of information technology. After several years hard work, college English teaching reform has made breakthrough progress, in the teaching idea, teaching mode and the teaching management of three different theoretical level and practical guidance level has preliminarily presents the characteristic of college English teaching reform in our country. In the later sections, we will put forward our unique perspectives on the reform with specialization on public English.

\section{The Proposed Methodology}

The Environment of Information Technology. In today's society is based on the computer Internet network, electronic signal as the carrier, the digital technology as the core of the information society. The information technology is profoundly influencing and changing our life and learning also bring the convenience and benefit for college English teaching. With network and multimedia as the core of integration of information technology and modern education teaching is one of the typical example, specifically, the integration of information technology and the modern education teaching refers to the information technology and a subject of the curriculum goals, structure, content implementation steps and the resources organically unifies in together, become a part of the teachers' teaching and students learning the subject, and have urged, enhance, strengthen and auxiliary learning in the subject [5-6].

After information technology and the integration of teaching, teachers should pay attention to the role of the conversion. The applications of information technology will improve the consciousness of teachers using the modern education technology and modern education idea, will greatly enhance the efficiency of teaching, will change the traditional teaching mode and, in turn, will greatly promote 
the process of English education reform, open a new path of English teaching reform, open up a new land for cultivating innovative talents. Theoretically, the applications of the information technology can be summarized as the follows. (1) To optimize the classroom teaching process. Information technology in comprehensive treatment and control symbols, language, text, sound, image, etc. have great ability, using the characteristic function, can change the abstract for specific, dynamic to the static and boring into lively so hard. (2) Presentation tools. Auxiliary English teaching using information technology, can create a lively teaching atmosphere, make the abstract, difficult to understand, hard to memory language knowledge into specific and visual image and the image of the symbol, thus make students willing to learn. (3) Development of teaching resources. Material information, the teaching material content to keep pace with the times and with the aid of network learning, in the repository, in view of the textbook content and research, expanding preview can break lay particular stress on the idea of the language art and ignore the social and cultural standard, causes the student to feel the spirit of the age and freshness. (4) To create the conditions of the autonomous learning. The integration of information technology and English course also demands to the students. Class mode transformation, emphasize the students as the center, emphasize students' active exploration, active in knowledge discovery and the knowledge in the active construction of meaning [7].

The application of information technology in English teaching reflects the requirements of our age, and this is a brand new information society that is a knowledge economy era. Swelling in the era of the knowledge economy, knowledge, information, traditional to teachers, classroom, teaching material as the center of the education system cannot meet the needs of the times and learners. With learners as the center, by means of the advanced education and technology, the lifelong education as the guiding ideology of the new education system is more and more shows its importance and necessity.

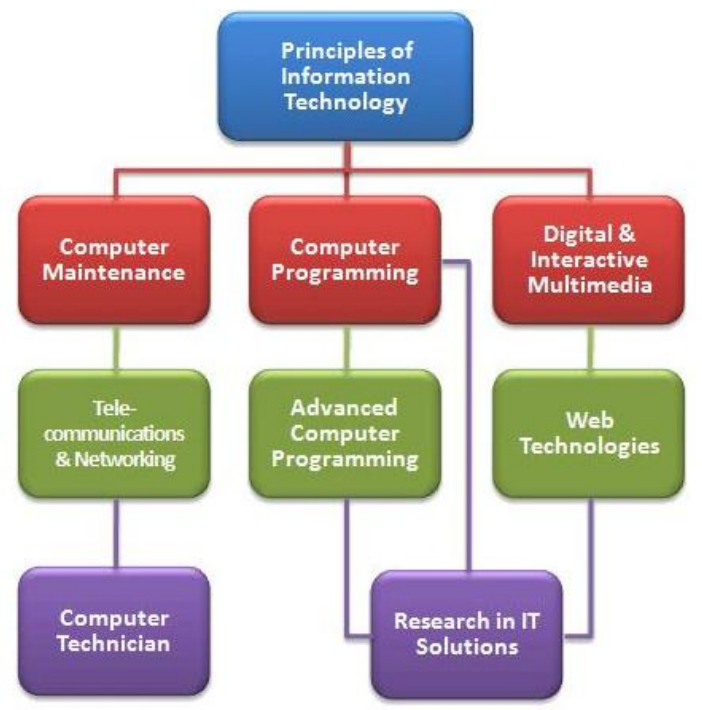

Figure 2. The Principles of the Information Technology

The English Education Reform. Higher vocational English teaching reform is a systematic project for a long time, in addition to the above aspects, we think that the English examination system reform, reform the teaching system, construction of language environment aspects such as the reform of form a complete set of series are imminent topic, this needs us to the joint efforts of every fellow workers and explore. To this end, we must first to the development direction of the college English teaching reform is a basic, the comprehensive and correct understanding of the direction of the college English teaching reform should be to develop comprehensive, diversity and high efficiency of college English teaching reform that could be generally reflected from the listed aspects [8].

- High efficiency of general college English teaching reform. New teaching model can not only effectively relieve the long plagued us such as lack of teachers, teachers' heavy workload, the level of students' individual differences. New teaching model that teachers have more 
time to participate in in-service training or all kinds of academic activities.

- A variety of college English teaching reform. Diversification of the teaching reform, make the most of the students are able to according to their own needs and interests, such as arranging learning, cultivate the students' ability of autonomous learning, stimulate the students' interest in learning, thus promotes the improvement of students' English ability.

- A full range of the college English teaching reform. New teaching patterns in addition to the language ability of students has very good promote, also help students individualized learning and the cultivation of the autonomous learning ability. New teaching model has inspired the enthusiasm of students to participate in teaching also raised their interest in learning English.

Students actively participate in teaching mode, the practical application as a starting point and basic method in the teaching of the English, to encourage students to think independently, stimulate students' interest in learning, the integration of the knowledge and experience, and through language training students' practical operating ability, to meet the different needs of students with appropriate, according to their aptitude, teaching activities by people. Application of basic information technology integrated practice course structure, content, method, means, to break through the general limitations of traditional means of teaching and the figure three reflects the keywords [9].

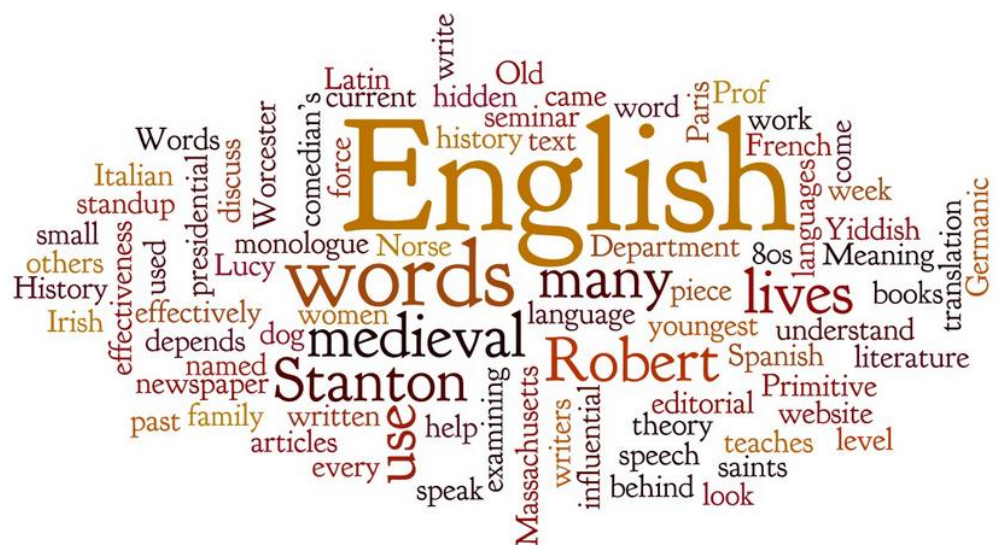

Figure 3. The Keywords of the Contemporary English Teaching Paradigm

The Public English Teaching Mode Reform. According to different teaching object, teaching mode, teaching content, teaching methods and teaching means are carried on the comprehensive reform and exploration for the non-English major students and English major students are put forward higher requirements. Although requirements vary, the implementation of object is different, but both are largely emphasized from the theory to the transformation of language ontology language tools are no longer just the purpose of college English teaching to teach students how to use the basic English communication tool, but from the thinking level expand students' knowledge, and develop students' comprehensive application ability [10].

Based on this, the author related data and combining its own teaching experience, gives following educational reform countermeasures and suggestions as follows. (1) Improve teachers' own quality. Teacher is the disseminator of knowledge and is the student's guidance, so the teachers should have strong professional knowledge and high levels of the literacy. In addition to master the advanced education teaching theory, familiar with the current of the 
latest developments in education, learn new teaching ideas, and can apply ideas to practice that makes the design and the organization of the future English teaching more flexible. (2) Some suggestions about construction of the teaching material. At present our country's economic development, higher vocational college graduates in today's society has become our country much-needed talent type has a broad prospect of its development. So, choose and write reflects the spirit of the times and higher vocational education requires series of English textbooks is one of the measures that we must reform the current. (3) Change the teaching mode. Create the corresponding scenario, on the basis of heard, the use of modern means of audio and video, and a variety of media, with the help of the environment atmosphere, action performance and so on to make learning content combined with the corresponding situation, help the students from the overall structure of perception and grasp the learning content.

\section{Conclusion}

In this paper, we conduct research on the public English teaching mode reform under environment of information technology. Improve the quality of higher vocational college English teaching, improve students' ability to freely use English, in order to prepare high qualified applied talents to meet the requirements of new situation, this is not achieved overnight, nor can be completed overnight, so we need to English teachers pay great efforts, continuously explore and research, summed up their own actual teaching experience, and to guide and to promote their own teaching. In the recent future, we will combine the latest education theory to enhance our current reform proposal.

\section{Acknowledgement}

Sponsored by Qing Lan Project.

\section{References}

[1] Kizildag, Ayse. "Teaching English in Turkey: Dialogues with teachers about the challenges in public primary schools." International Electronic Journal Environmental Education 1.3 (2009).

[2] Yamin, Liu. "A new exploration of Level-based College English Teaching Model [J]." Foreign Language World 4 (2009): 003.

[3] Chen, Zan, and Christine Goh. "Teaching oral English in higher education: Challenges to EFL teachers." Teaching in Higher Education 16.3 (2011): 333-345.

[4] Huang, Fang. "College English teaching innovation for cultivating excellent engineering talents-Based on the innovation of university of Shanghai for science and technology." Computer-Assisted Foreign Language Education 1 (2011): 15-19.

[5] Shin, Jeeyoung, Zohreh R. Eslami, and Wen-Chun Chen. "Presentation of local and international culture in current international English-language teaching textbooks." Language, Culture and Curriculum 24.3 (2011): 253-268.

[6] Lang, Chen. "On Cultivation of Metaphoric Competence in Second Language Teaching [J]." Foreign Language Research 5 (2010): 014.

[7] Kirkpatrick, Andy. "Teaching English across cultures. What do English language teachers need to know to know how to teach English." (2007): 20.

[8] GE, Shi-li, and Xiao-xiao CHEN. "The Key Problems and Solutions in Automated Essay Scoring for College English Teaching in China [J]." Shandong Foreign Language Teaching Journal 3 (2009): 006. 
[9] Kurihara, Yuka, and Keiko K. Samimy. "The impact of a US teacher training program on teaching beliefs and practices: A case study of secondary school level Japanese teachers of English." JALT JOURNAL 29.1 (2007): 99.
[10] YE, Hui-jun, and Peng WANG. "Reflections on native culture in the teaching of English [J]." Journal of Hebei Normal University (Educational Science Edition) 9 (2010): 022. 